\title{
Novel Simplified and Rapid Method for Screening and Isolation of Polyunsaturated Fatty Acids Producing Marine Bacteria
}

\author{
Ashwini Tilay and Uday Annapure \\ Food Engineering and Technology Department, Institute of Chemical Technology, Matunga, Mumbai 400 019, India \\ Correspondence should be addressed to Uday Annapure, udayannapure@gmail.com \\ Received 17 March 2012; Revised 27 May 2012; Accepted 28 May 2012 \\ Academic Editor: Manuel Canovas
}

Copyright (๑) 2012 A. Tilay and U. Annapure. This is an open access article distributed under the Creative Commons Attribution License, which permits unrestricted use, distribution, and reproduction in any medium, provided the original work is properly cited.

Bacterial production of polyunsaturated fatty acids (PUFAs) is a potential biotechnological approach for production of valuable nutraceuticals. Reliable method for screening of number of strains within short period of time is great need. Here, we report a novel simplified method for screening and isolation of PUFA-producing bacteria by direct visualization using the $\mathrm{H}_{2} \mathrm{O}_{2}$-plate assay. The oxidative stability of PUFAs in growing bacteria towards added $\mathrm{H}_{2} \mathrm{O}_{2}$ is a distinguishing characteristic between the PUFAs producers (no zone of inhibition) and non-PUFAs producers (zone of inhibition) by direct visualization. The confirmation of assay results was performed by injecting fatty acid methyl esters (FAMEs) produced by selected marine bacteria to Gas ChromatographyMass Spectrometry (GCMS). To date, this assay is the most effective, inexpensive, and specific method for bacteria producing PUFAs and shows drastically reduction in the number of samples thus saves the time, effort, and cost of screening and isolating strains of bacterial PUFAs producers.

\section{Introduction}

Microbial lipids are a diverse group of compounds with a number of vital nutraceutical and pharmaceutical applications and utilized commercially since the 1980s. These microbial lipids or polyunsaturated fatty acids (PUFAs) are obtained from various sources. Now a day, microorganismproduced (algae/fungi/bacteria) PUFAs are commercially competitive with plant and fish oils.

PUFAs are the fatty acids having more than one double bond. Eicosapentaenoic acid (EPA, 20:5,n-3) and docosahexaenoic acid (DHA, $22: 6, n-3$ ) are the important $n-3$ fatty acids, while arachidonic acid (AA, $20: 4, n-6$ ) is a vital $n-6$ fatty acid. EPA and DHA are important for prevention of arthrosclerosis, cancer, rheumatoid arthritis, psoriasis, and diseases of old age such as Alzheimer's and age-related macular degeneration $[1,2]$. AA and DHA are of special importance in the brain and blood vessels and are considered essential for pre- and postnatal brain and retinal development [3]. Eicosanoids such as prostaglandins, prostacyclins, and leukotrienes derived from $n-3$ PUFA are also important in new-born and infant development, modulatory vascular resistance, and wound healing [4-6]. PUFAs are either directly available as components of the diet or produced from precursors like linoleic acid (LA, C18:2n-6) and a-linolenic acid (ALA, C18:3n-3) [7].

Accordingly, PUFAs are highly important substances in the pharmaceutical, medical, and nutritional fields. Recent investigations have focused on microorganisms as alternative natural source for production of oil containing PUFAs. These are potentially promising lipid source because of their high growth rates in simple media and simplicity of their manipulation. As traditional sources of $n-3$ fatty acids such as fish oil continue to diminish, identification of alternate sources will become crucial. Marine microorganisms represent one of the less explored sources of biologically active natural products. Novel compounds with various bioactivities such as antibiotic, antitumor, cytotoxic, and anti-inflammatory, have been isolated and elucidated from this source [8].

Considering importance of PUFAs, many researchers have tried to isolate and screen marine organisms for these 


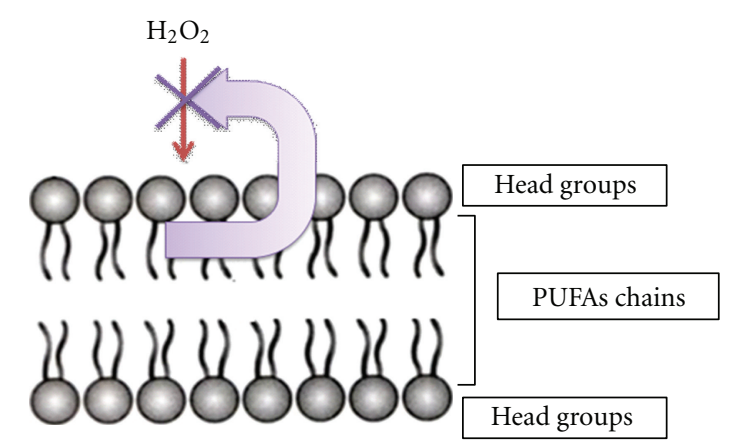

Figure 1: Proposed mode of action for the $\mathrm{H}_{2} \mathrm{O}_{2}$-plate assay method.

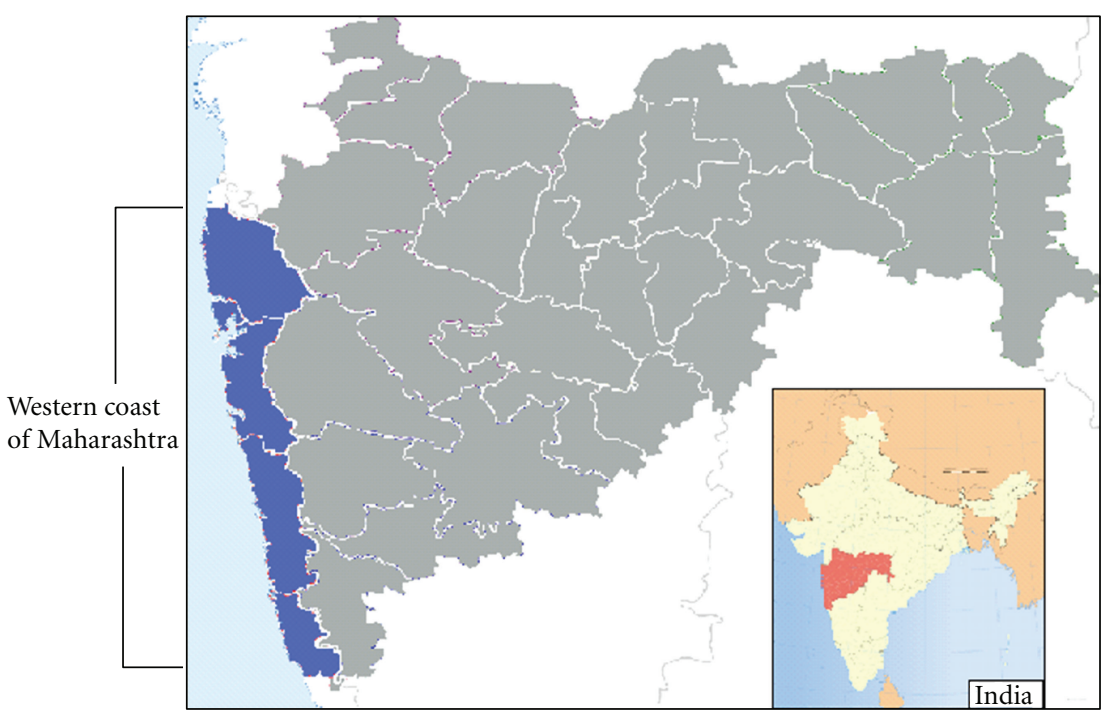

FIGURE 2: Map of western coast region of Maharashtra (INDIA).

bioactive compounds. The next step after isolation of microorganisms is screening. Ideally, selective procedure would allow the detection and isolation of microorganisms producing the desired metabolite. This primary screening should be rapid, inexpensive, predictive, specific, but effective over a broad range and should be applicable to large scale. Sometimes primary screening is time consuming and labour intensive when a large number of isolates have to be screened to identify a few potential ones. However, this is possibly the most critical step since it eliminates the large bulk of unwanted isolates, which are either nonproducers or producers of known compounds.

Screening and isolation method for long chain PUFA by marine protistan was reported but judged unsuitable by Bowles et al. for high throughput screening. The $\mathrm{H}_{2} \mathrm{O}_{2}$ plate assay method can be applied to a wide range of bacterial samples collected from different regions or from different animal sources. During screening of random hundreds of different marine bacterial samples, we have successfully discovered new strains of marine microorganisms with the special characteristic to produce PUFAs.

Generally, PUFAs are the molecules which are most susceptible to oxygen and reactive oxygen species (ROS) [10].
There are facts that PUFAs are stable when they are in vivo against oxidative stresses caused by ROS. This study was based on application of antioxidative effect of PUFA against ROS (Figure 1), for rapid screening of large number of marine isolates. However, no information regarding the screening of PUFAs producing marine bacteria has been reported. In the following strategy, we have presented qualitative method for rapid screening of PUFA producers.

\section{Experimental Procedures}

2.1. Materials. All the chemicals and media components used in the present study were AR grade and purchased from Hi Media Ltd, Mumbai, India. Sodium azide was purchased from S.D. Fine Chemicals Limited, Mumbai, India.

\subsection{Media and Culture Conditions for Marine Microorganisms}

2.2.1. Sample Collection. Various samples were collected from different regions of western coast of Maharashtra, India (Figure 2) and were brought to our laboratory for further investigation. 


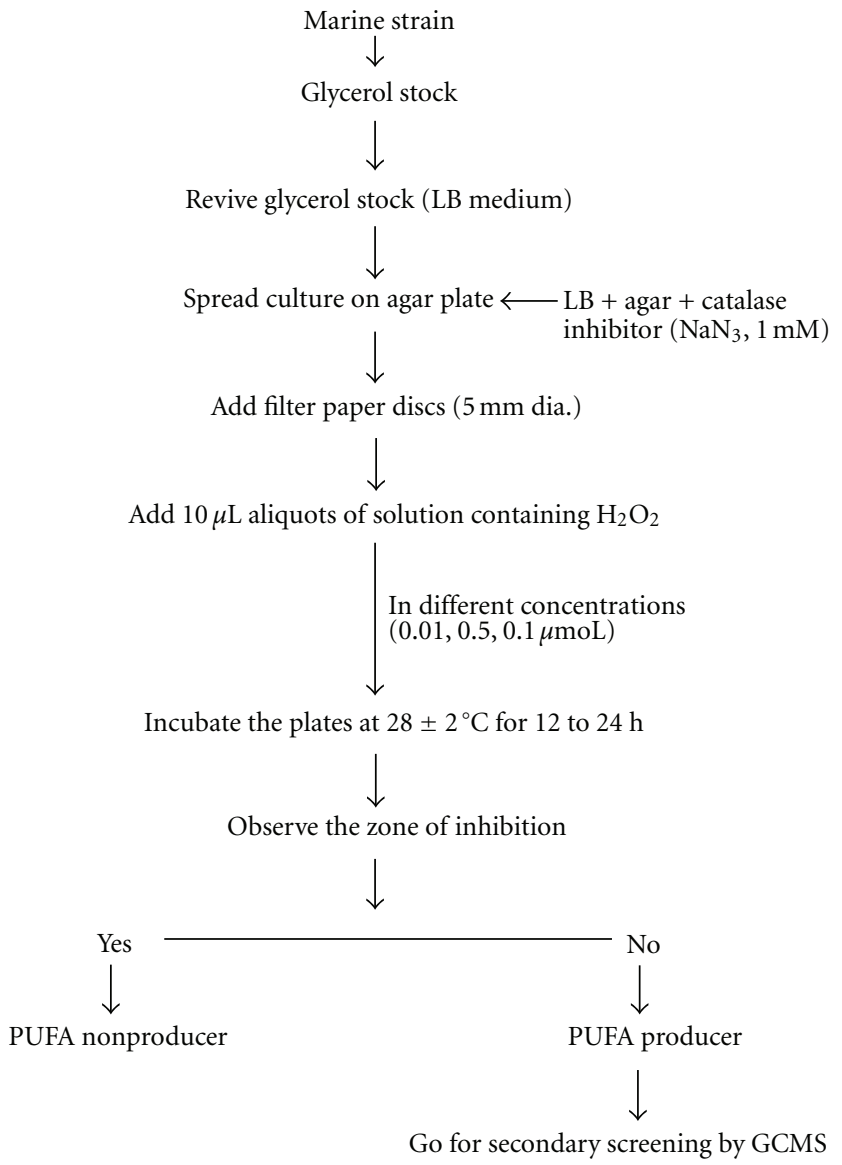

FIGURE 3: Protocol for primary screening of marine isolates.

2.2.2. Isolation of Marine Bacteria. The collected samples were serially diluted and plated over nutrient agar plates. The inoculated plates were incubated at $28 \pm 2^{\circ} \mathrm{C}$ for $24-48 \mathrm{~h}$. After incubation, the selected bacterial colonies were purified and subcultured on nutrient agar medium for further investigation. All the marine isolates were preserved in glycerol stocks under $(-) 20^{\circ} \mathrm{C}$.

2.3. Primary Screening of Marine Bacterial Isolates by $\mathrm{H}_{2} \mathrm{O}_{2}$ Plate Assay. About 100 isolated marine strains were randomly selected and screened for PUFA production (Figure 3 ). All the selected marine cultures were cultivated in LuriaBertani (LB) medium (1\% Tryptone, 0.5\% Yeast Extract, 1\% $\mathrm{NaCl}$ ) at $28 \pm 2{ }^{\circ} \mathrm{C}$ for $24 \mathrm{~h}, 180 \mathrm{rpm}$. To this medium, $0.5 \%$ $\mathrm{NaCl}$ was added for proper growth of marine isolates rather than using artificial seawater [11]. To find out response of bacteria to $\mathrm{H}_{2} \mathrm{O}_{2}$, bacterial culture reaching an optical density at $660 \mathrm{~nm}$ of 1.0 was used and spreaded over plate containing $\mathrm{LB}$ medium and sodium azide $\left(\mathrm{NaN}_{3}, 1 \mathrm{mM}\right)$. On a surface filter paper discs of diameter $5 \mathrm{~mm}$ were placed and ten microliter aliquots of solution containing different concentration of $\mathrm{H}_{2} \mathrm{O}_{2}(0.01,0.5,1.0 \%$ prepared from $30 \%$ stock solution) were added on filter disc. Plates were then incubated at $28 \pm 2^{\circ} \mathrm{C}$ for $24 \mathrm{~h}$. Zone of inhibition was observed and further confirmation of PUFA producers was done by GCMS.

\subsection{Secondary Screening and Confirmation}

2.4.1. Media and Cultivation Conditions. Amongst all screened marine bacterial cultures, the positive strains were selected on the basis of no zone of inhibition (PUFA producers) and used further for secondary screening and confirmation for the production of PUFA. A loopful of the bacterial culture grown on previously preserved LB medium slants was transferred into $20 \mathrm{~mL}$ of LB broth in a $100 \mathrm{~mL}$ Erlenmyer flask and left on a shaker at $28 \pm 2^{\circ} \mathrm{C}$ for $24 \mathrm{~h}$ at $180 \mathrm{rpm}$. One $\mathrm{mL}$ of culture was transferred into $50 \mathrm{~mL}$ fresh sterilized $\mathrm{LB}$ broth and left on shaker at $28 \pm 2^{\circ} \mathrm{C}$ for $24 \mathrm{~h}$ at $180 \mathrm{rpm}$. Cell biomass was harvested from fermented media by centrifugation at $8000 \mathrm{rpm}$ at $25 \pm 2^{\circ} \mathrm{C}$ for $10 \mathrm{~min}$. The biomass was washed thoroughly with distilled water and was finally dried at $50^{\circ} \mathrm{C}$ overnight.

2.4.2. Direct Lipid Extraction and Esterification of Fatty Acids. A rapid direct extraction and esterification method was 


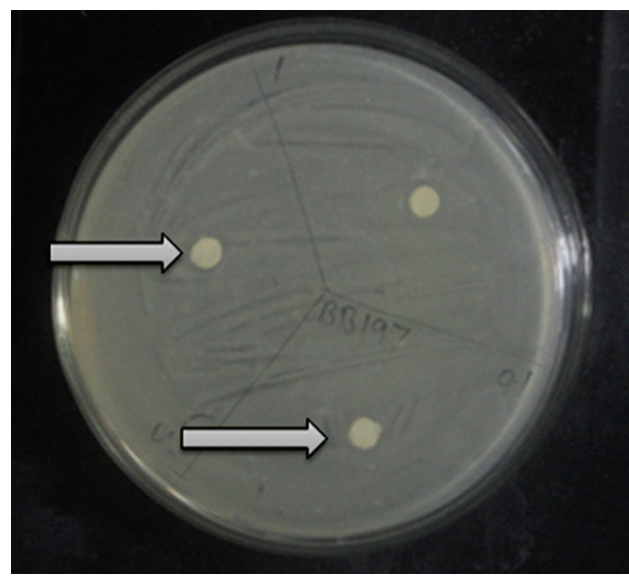

(a) No zone of inhibition (PUFA producer)

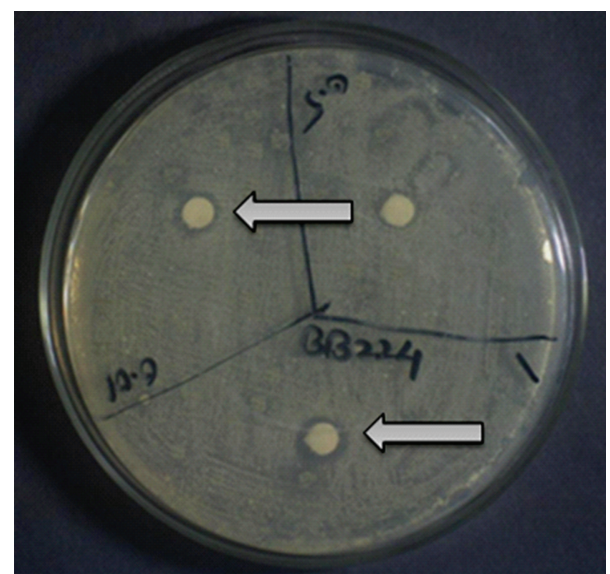

(b) Zone of inhibition (PUFA non-producer)

Figure 4: $\mathrm{H}_{2} \mathrm{O}_{2}$-plate assay.

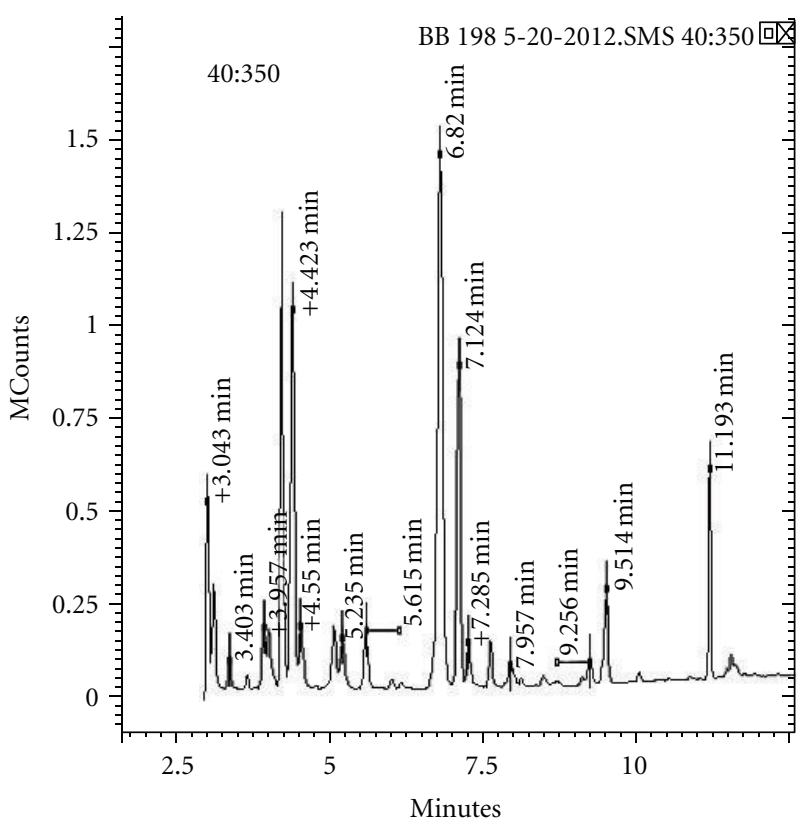

FIGURE 5: Gas chromatogram showing fatty acid profile of a selected marine isolate after primary screening.

developed and applied in this study. Extraction of lipids from biomass was performed according to the modified procedure of Hoshi et al. [12]. Lipids were extracted for 3-4 h with a 3 times volume of chloroform/methanol $(2: 1, \mathrm{v} / \mathrm{v})$ containing $15 \mathrm{mg}$ BHT for prevention of oxidation of PUFAs [13]. Esterification was done by adding $0.2 \mathrm{~mL}$ of $20 \mathrm{mM}$ cupric acetate monohydrate in methanol and $1 \mathrm{~mL}$ of $0.5 \mathrm{~N}$ $\mathrm{HCl}$ in methanol was added, and the mixture was left for the specified time $(2-3 \mathrm{~h})$ at room temperature or at $28 \pm 2^{\circ} \mathrm{C}$. The reaction was stopped with the addition of $0.4 \mathrm{~mL}$ of water. The lower chloroform layer was pooled and then evaporated and was concentrated by rotary evaporator (Buchi Rotavapor) at $35^{\circ} \mathrm{C}$. Finally the fatty acid methyl esters (FAME) were dissolved in hexane $(1 \mathrm{~mL})$, filtered through Whatman No. 1 filter paper, and analysed by GCMS.
2.4.3. Analysis PUFA by GCMS. Analysis of the FAME was performed by GCMS using slightly modified procedure [14]. All compounds were identified by comparison of their retention times with those of known standards and confirmed by GCMS using Varian 220-MS ion trap mass spectrometer (Varian, Inc. Walnut Creek, CA) connected to Varian 450-GC equipped with CP-SIL 88 capillary column $(25 \mathrm{~m} \times 0.25 \mathrm{~mm}$ i.d. $\times 0.39 \mathrm{~mm}$ OD, Varian). The injector was maintained at $250^{\circ} \mathrm{C}$, and the column oven was programmed to increase from 160 to $220^{\circ} \mathrm{C}$ at $7^{\circ} \mathrm{C}$ min and then maintained at $220^{\circ} \mathrm{C}$ for $10 \mathrm{~min}$. Split ratio was adjusted to $1: 20$. Helium was used as the carrier gas and flow rate was maintained at $1 \mathrm{~mL} / \mathrm{min}$. GCMS was operated at an ionization voltage of $70 \mathrm{eV}$ and trap temperature at $220^{\circ} \mathrm{C}$ with mass range of $40-350$ atomic mass units. 
TABLE 1: Screening of marine strains using $\mathrm{H}_{2} \mathrm{O}_{2}$-plate assay method.

(a)

\begin{tabular}{|c|c|c|c|c|c|c|c|c|c|c|c|}
\hline \multirow{2}{*}{ No. } & \multirow{2}{*}{ Strain } & \multicolumn{3}{|c|}{$\mathrm{H}_{2} \mathrm{O}_{2}^{@}(\%)$} & \multirow{2}{*}{$\begin{array}{l}\text { PUFA* } \\
\text { +ve/-ve }\end{array}$} & \multirow[t]{2}{*}{ No. } & \multirow[t]{2}{*}{ Strain } & \multicolumn{3}{|c|}{$\mathrm{H}_{2} \mathrm{O}_{2}^{@}(\%)$} & \multirow{2}{*}{$\begin{array}{l}\text { PUFA* }^{*} \\
\text { +ve/-ve }\end{array}$} \\
\hline & & 0.1 & 0.5 & 1.0 & & & & 0.1 & 0.5 & 1.0 & \\
\hline 1 & JAY B 8 & - & - & - & $-\mathrm{ve}$ & 26 & TH B 9 & - & - & - & - ve \\
\hline 2 & TAV B 31 & - & - & - & - ve & 27 & DI BB 152 & - & - & + & $+\mathrm{ve}$ \\
\hline 3 & PA BB 8 & - & - & - & $-\mathrm{ve}$ & 28 & TH BB 21 & + & ++ & ++ & + ve \\
\hline 4 & TH BB 31 & - & - & - & - ve & 29 & ALI B 71 & - & - & - & - ve \\
\hline 5 & DIG BB 113 & - & - & - & - ve & 30 & R BB 11 & + & + & - & $+v e$ \\
\hline 6 & TH BB 22 & - & - & - & $-\mathrm{ve}$ & 31 & BB 82 & - & - & - & - ve \\
\hline 7 & PA BB 3 & - & - & - & -ve & 32 & JAY B 12 & - & - & - & - ve \\
\hline 8 & TH BB 15 & - & - & - & $-\mathrm{ve}$ & 33 & TH BB 22 & - & - & - & - ve \\
\hline 9 & P BB 13 & - & - & - & $-\mathrm{ve}$ & 34 & MAN BB 358 & - & - & - & $-\mathrm{ve}$ \\
\hline 10 & DIG BB 4 & + & + & + & + ve & 35 & P BB 9 & - & - & - & - ve \\
\hline 11 & М ВВ 318 & - & + & ++ & $+v e$ & 36 & TH 33 & - & - & - & - ve \\
\hline 12 & DI BB 146 & - & - & + & +ve & 37 & R 23 & - & - & - & $-\mathrm{ve}$ \\
\hline 13 & GP B 2 & - & + & ++ & + ve & 38 & RAT B 18 & - & - & - & $-\mathrm{ve}$ \\
\hline 14 & AH B 53 & - & + & ++ & + ve & 39 & RA 21 & - & - & - & - ve \\
\hline 15 & MD BB 345 & + & + & ++ & $+v e$ & 40 & MD BB 325 & - & - & - & - ve \\
\hline 16 & PA BB 8 & - & + & ++ & + ve & 41 & SHI BB 2 & - & - & - & $-\mathrm{ve}$ \\
\hline 17 & TH BB 5 & - & + & + & + ve & 42 & PA B 12 & - & - & - & $-\mathrm{ve}$ \\
\hline 18 & MAN BB 200 & - & - & - & $-\mathrm{ve}$ & 43 & PA BB 4 & - & - & - & - ve \\
\hline 19 & MAN BB 361 & - & - & - & - ve & 44 & TH BB 27 & - & - & - & - ve \\
\hline 20 & AL BB 156 & - & + & ++ & $+v e$ & 45 & TH BB 25 & - & - & - & - ve \\
\hline 21 & TH BB 20 & - & + & ++ & $+v e$ & 46 & BB 227 & + & + & ++ & $+v e$ \\
\hline 22 & TAV B 27 & + & + & ++ & $+v e$ & 47 & TH BB 30 & - & - & - & - ve \\
\hline 23 & ALI B 51 & + & + & ++ & + ve & 48 & MAN 10 & - & - & - & - ve \\
\hline 24 & BB 232 & - & + & + & $+v e$ & 49 & BB 72 & - & - & - & - ve \\
\hline 25 & MAN 353 & - & - & + & + ve & 50 & R 37 & - & - & - & - ve \\
\hline
\end{tabular}

${ }^{@}$ describes zone of inhibition due to presence $\mathrm{H}_{2} \mathrm{O}_{2} ;+/++$ describes growth of microorganisms or no zone of inhibition due to presence of PUFA. * PUFA +ve denotes PUFA producer and -ve denotes PUFA nonproducer.

Note: highlighted strains were further screened by secondary analysis.

(b)

\begin{tabular}{|c|c|c|c|c|c|c|c|c|c|c|c|}
\hline \multirow{2}{*}{ No. } & \multirow{2}{*}{ Strain } & \multicolumn{3}{|c|}{$\mathrm{H}_{2} \mathrm{O}_{2}^{@}(\%)$} & \multirow{2}{*}{$\begin{array}{l}\text { PUFA* } \\
+ \text { ve/-ve }\end{array}$} & \multirow[t]{2}{*}{ No. } & \multirow[t]{2}{*}{ Strain } & \multicolumn{3}{|c|}{$\mathrm{H}_{2} \mathrm{O}_{2}^{@}(\%)$} & \multirow{2}{*}{$\begin{array}{l}\text { PUFA* }^{*} \\
\text { +ve/-ve }\end{array}$} \\
\hline & & 0.1 & 0.5 & 1.0 & & & & 0.1 & 0.5 & 1.0 & \\
\hline 51 & TH BB 19 & ++ & ++ & + & +ve & 76 & MD BB 312 & - & - & - & - ve \\
\hline 52 & BB 83 & + & + & + & + ve & 77 & MAN BB 63 & - & - & - & -ve \\
\hline 53 & RAT B 3 & - & - & - & -ve & 78 & TH BB 28 & - & - & - & -ve \\
\hline 54 & AK BB 189 & - & - & - & $-v e$ & 79 & JAY B 38 & - & - & - & - ve \\
\hline 55 & BB 201 & - & - & - & - ve & 80 & BB 20 & + & - & - & + ve \\
\hline 56 & MAN 352 & - & - & - & -ve & 81 & P BB 22 & - & - & - & $-\mathrm{ve}$ \\
\hline 57 & TH 33 & + & - & - & + ve & 82 & RAT B 85 & - & - & - & - ve \\
\hline 58 & BB 198 & ++ & + & + & + ve & 83 & SHI BB 2 & - & - & - & - ve \\
\hline 59 & R 13 & - & - & - & -ve & 84 & PA BB 33 & - & - & - & - ve \\
\hline 60 & HAR BB 118 & - & - & - & - ve & 85 & MD BB 122 & - & - & - & - ve \\
\hline 61 & RO BB 24 & + & - & - & + ve & 86 & MAN BB 229 & + & - & - & $+\mathrm{ve}$ \\
\hline 62 & TH BB 24 & - & - & - & - ve & 87 & TH BB 82 & - & - & - & $-\mathrm{ve}$ \\
\hline 63 & SRK 6 & - & - & - & - ve & 88 & DIG BB 122 & - & - & - & - ve \\
\hline 64 & BB 245 & - & - & - & - ve & 89 & G BB 89 & - & - & - & - ve \\
\hline 65 & BB 86 & - & - & - & $-\mathrm{ve}$ & 90 & MAN 63 & - & - & - & $-\mathrm{ve}$ \\
\hline 66 & G BB 249 & - & - & - & - ve & 91 & AL BB 148 & - & - & - & $-\mathrm{ve}$ \\
\hline 67 & DIG BB 108 & - & - & - & - ve & 92 & TAV B 47 & - & - & - & - ve \\
\hline 68 & MD BB 338 & - & - & - & - ve & 93 & R 39 & - & - & - & -ve \\
\hline
\end{tabular}


(b) Continued.

\begin{tabular}{|c|c|c|c|c|c|c|c|c|c|c|c|}
\hline \multirow{2}{*}{ No. } & \multirow{2}{*}{ Strain } & \multicolumn{3}{|c|}{$\mathrm{H}_{2} \mathrm{O}_{2}^{@}(\%)$} & \multirow{2}{*}{$\begin{array}{l}\text { PUFA* }^{*} \\
\text { +ve/-ve }\end{array}$} & \multirow[t]{2}{*}{ No. } & \multirow[t]{2}{*}{ Strain } & \multicolumn{3}{|c|}{$\mathrm{H}_{2} \mathrm{O}_{2}^{@}(\%)$} & \multirow{2}{*}{$\begin{array}{l}\text { PUFA* } \\
\text { +ve/-ve }\end{array}$} \\
\hline & & 0.1 & 0.5 & 1.0 & & & & 0.1 & 0.5 & 1.0 & \\
\hline 69 & TH BB 166 & - & - & - & - ve & 94 & BB 289 & + & - & - & + ve \\
\hline 70 & MAN BB 364 & - & - & - & - ve & 95 & JAY B 23 & - & - & - & - ve \\
\hline 71 & SRK 23 & - & - & - & - ve & 96 & DI BB 278 & - & - & - & - ve \\
\hline 72 & ТН BB 83 & - & - & - & - ve & 97 & ТH В 34 & - & - & - & $-v e$ \\
\hline 73 & BB 39 & - & - & - & - ve & 98 & AK BB 148 & - & - & - & $-\mathrm{ve}$ \\
\hline 74 & TAV B 29 & - & - & - & - ve & 99 & HAR BB 72 & - & - & - & - ve \\
\hline 75 & SHE BB 29 & - & - & - & -ve & 100 & RO BB 41 & - & - & - & - ve \\
\hline
\end{tabular}

${ }^{\circledR}$ describes zone of inhibition due to presence $\mathrm{H}_{2} \mathrm{O}_{2} ;+/++$ describes growth of microorganisms or no zone of inhibition due to presence of PUFA.

* PUFA +ve denotes PUFA producer and -ve denotes PUFA nonproducer.

Note: highlighted strains were further screened by secondary analysis.

TABLE 2: Fatty acid profile of marine isolate produced after fermentation in secondary screening.

\begin{tabular}{|c|c|c|c|c|c|c|c|c|c|c|}
\hline \multirow{2}{*}{$\begin{array}{l}\text { Fatty acid methyl esters } \\
\text { (MUFA + PUFA) }\end{array}$} & \multicolumn{10}{|c|}{ Selected strains for secondary screening and their fatty acid profile } \\
\hline & M BB 318 & BB 83 & ALI B 51 & BB 227 & MD BB 345 & BB 198 & DIG BB 4 & TAV B 27 & TH BB 19 & TH BB 21 \\
\hline Pentadecanoic acid & + & + & + & + & + & + & - & - & - & - \\
\hline Hexadecanoic acid & + & + & + & + & + & + & + & + & + & + \\
\hline 14-methylhexadecanoate & + & - & + & + & + & + & - & - & - & - \\
\hline Margaric acid & + & + & + & + & + & + & - & - & - & - \\
\hline Oleic acid & + & + & + & + & + & + & - & + & + & + \\
\hline 16-Octadecenoic acid & - & - & - & - & - & - & + & - & - & - \\
\hline 7,10-Octadecadienoic acid & - & - & - & - & - & - & + & - & - & - \\
\hline Linoleic acid & + & + & + & + & + & + & - & + & + & + \\
\hline 7,10,13-Hexadecatrienoic acid & - & - & - & - & - & - & + & - & - & - \\
\hline$\gamma$-Linolenic acid & - & - & - & - & - & + & - & - & - & - \\
\hline Linolenic acid & + & + & + & + & + & + & - & + & + & + \\
\hline Eicosanoic acid & + & - & - & - & - & - & - & - & - & - \\
\hline Arachidonic acid & - & - & - & - & - & + & - & - & - & - \\
\hline Eicosapentaenoic acid & - & - & - & - & - & + & - & - & - & - \\
\hline
\end{tabular}

Note: MUFA- monounsaturated fatty acid.

\section{Results and Discussion}

3.1. Primary Screening of Marine Bacterial Isolates by $\mathrm{H}_{2} \mathrm{O}_{2}$ Plate Assay. In $\mathrm{H}_{2} \mathrm{O}_{2}$-plate assay method, the cells which are susceptible to externally-added $\mathrm{H}_{2} \mathrm{O}_{2}$ cannot able to grow suitably and thus shows a zone of inhibition which is dependant on added concentration of $\mathrm{H}_{2} \mathrm{O}_{2}$ on filter paper disc. The diameter of zone of inhibition is directly proportional to the concentration of added $\mathrm{H}_{2} \mathrm{O}_{2}$. The contradictory situation was observed for bacterial cells which produce PUFA. These cells able to grow in presence of added $\mathrm{H}_{2} \mathrm{O}_{2}$ on filter paper disc. As shown in Figure 4(a) the bacteria were grown even in presence of $\mathrm{H}_{2} \mathrm{O}_{2}$, due to the membrane-shielding effects of PUFAs. In most cases, PUFAs are among the molecules most vulnerable to oxygen and ROS, Okuyama et al. [10]. In Figure 4(b) the bacterial cells which were PUFA deficient or nonproducers were hampered by $\mathrm{H}_{2} \mathrm{O}_{2}$ and hence could not able to grow where zone of inhibition was directly proportional to the concentration of $\mathrm{H}_{2} \mathrm{O}_{2}$ added. Higher the concentration of $\mathrm{H}_{2} \mathrm{O}_{2}$ more will be the zone of inhibition.
To confirm that, growth of bacteria in presence of $\mathrm{H}_{2} \mathrm{O}_{2}$ is in reality mainly due to presence of PUFA; $\mathrm{NaN}_{3}$ was added in to the media which is a very powerful inhibitor of catalase. If microorganism is producing catalase enzyme, $\mathrm{NaN}_{3}$ inhibits catalase enzyme [15] which helps in interfering and promotes the actual interpretation of plate assay. About $1 \mathrm{mM}$ concentration of $\mathrm{NaN}_{3}$ was used during experimental study. The concentration should be an adequate amount to act as catalase inhibitor at the same time should not be antimicrobial in nature. The concentration of $\mathrm{NaN}_{3}$ was decided from reported studied by Teixeira and Mota [16]. Out of selected 100 strains, 26 strains were found to give false positive results (Tables $\mathrm{I}(\mathrm{a})$ and $\mathrm{I}(\mathrm{b})$ ). Out of 26,10 strains were selected which gave false positive results at all $\mathrm{H}_{2} \mathrm{O}_{2}$ concentrations used during plate assay method. They were screened for further secondary analysis and confirmation.

EPA- and DHA-expressing bacteria were reported to be more resistant to exogenous $\mathrm{H}_{2} \mathrm{O}_{2}$ [10]. But there were no investigations whether other long chain (LC) PUFAs than EPA and DHA have similar effects. The bacterial cell gets protected by the effect of EPA that has reported earlier [10]. 
The membrane-shielding effects of $n$ - 3 LC-PUFAs have been shown only for bacterial cells producing EPA $[17,18]$. From the study we have observed that other than EPA and DHA other PUFA might be responsible for the same protecting effect of exogenous $\mathrm{H}_{2} \mathrm{O}_{2}$ and our hypothesis was well supported with studied carried out by Okuyama et al. [10].

As shown in Figure 5, the fatty acid profile obtained from the bacterial culture which was able to grow in presence of $\mathrm{H}_{2} \mathrm{O}_{2}$ shows mainly AA production along with EPA. Hence, from this study not only EPA and DHA but also other PUFAs like AA act as the shield molecules against such oxidative challenges exogenously and endogenously raised in marine environments. There are some reports on protective effect of DHA against the external hydrogen peroxide [19]. It was reported that PUFAs including $n$-3 PUFAs are the molecules which are most susceptible to oxygen and reactive oxygen species (ROS). But from our study, it was observed that not only $n$-3 PUFAs are susceptible to oxygen and reactive oxygen species but also $n-6$ PUFAs like AA may behave in same way [20].

3.2. Secondary Screening and Confirmation. From few selected false positive strains all strains were found to give remarkable response when their lipid extract was injected into GCMS. The mass spectra of all selected strains were found to produce different kind of fatty acids. Some of them were found to produce AA and EPA which are very essential PUFAs from nutritional point of view. The fatty acid profile of 10 selected strains was shown in Table 2 that provides the information about different fatty acids produced by selected marine bacteria after primary screening using $\mathrm{H}_{2} \mathrm{O}_{2}$-plate assay. Hence this method is a qualitative estimation of PUFAs produced from microorganisms.

\section{Conclusion}

Thus, the present investigation has clearly revealed the presence of PUFAs in marine bacteria in the marine samples by newly developed novel simplified and rapid plate culture method for screening of PUFAs-producing marine bacteria; collected from different regions of western coast of Maharashtra, India. GCMS analysis studies confirmed the actual production of PUFA in various selected marine bacteria after primary screening. In order to minimise the time required for analysis as well as economic loss, this method gives the suitable solution for large number of samples screening which are abundant in the marine environment.

\section{Acknowledgment}

Authors are thankful to the University Grants Commission, Government of India, India, for providing financial assistance during the course of this research.

\section{References}

[1] C. A. Drevon, I. Baksaas, and H. E. Krokan, Omega-3 Fatty Acids: metabolism and Biological Effects, Birkhäuser, Basel, Switzerland, 1993.
[2] A. P. Simopoulos, A. Leaf, and N. Salem, "Essentiality of and recommended dietary intakes for omega- 6 and omega- 3 fatty acids," Annals of Nutrition and Metabolism, vol. 43, no. 2, pp. 127-130, 1999.

[3] M. A. Crawford, "Placental delivery of arachidonic and docosahexaenoic acids: implications for the lipid nutrition of preterm infants," American Journal of Clinical Nutrition, vol. 71, no. 1, pp. 275S-284S, 2000.

[4] S. Bergstrom, H. Danielsson, and B. Samuelsson, "The enzymatic formation of prostaglandin E2 from arachidonic acid," Biochimica et Biophysica Acta, vol. 90, pp. 207-210, 1964.

[5] D. A. Van Dorp, R. K. Beerthuis, D. H. Nugteren, and H. Vonkeman, "The biosynthesis of prostaglandins," Biochimica et Biophysica Acta, vol. 90, no. 1, pp. 204-207, 1964.

[6] B. A. Jakschik, A. R. Sams, H. Sprecher, and P. Needleman, "Fatty acid structural requirements for leukotriene biosynthesis," Prostaglandins, vol. 20, no. 2, pp. 401-410, 1980.

[7] H. Okuyama, T. Kobayashi, and S. Watanabe, "Dietary fatty acids-The N-6/N-3 balance and chronic elderly diseases. Excess linoleic acid and relative N-3 deficiency syndrome seen in Japan," Progress in Lipid Research, vol. 35, no. 4, pp. 409457, 1996.

[8] J. Kobayashi, "Bioactive products from marine micro-and macro-organisms," Pure and Applied Chemistry, vol. 71, no. 6, pp. 1123-1126, 1999.

[9] R. D. Bowles, A. E. Hunt, G. B. Bremer, M. G. Duchars, and R. A. Eaton, "Long-chain n-3 polyunsaturated fatty acid production by members of the marine protistan group the thraustochytrids: screening of isolates and optimisation of docosahexaenoic acid production," Journal of Biotechnology, vol. 70, no. 1-3, pp. 193-202, 1999.

[10] H. Okuyama, Y. Orikasa, and T. Nishida, "Significance of antioxidative functions of eicosapentaenoic and docosahexaenoic acids in marine microorganisms," Applied and Environmental Microbiology, vol. 74, no. 3, pp. 570-574, 2008.

[11] J. D. Oliver and R. R. Colwell, "Extractable lipids of gram negative marine bacteria: fatty acid composition," International Journal of Systematic Bacteriology, vol. 23, no. 4, pp. 442-458, 1973.

[12] M. Hoshi, M. Williams, and Y. Kishimoto, "Esterification of fatty acids at room temperature by chloroform methanolic $\mathrm{HCl}$ cupric acetate," Journal of Lipid Research, vol. 14, no. 5, pp. 599-601, 1973.

[13] M. H. Cheng, T. H. Walker, G. J. Hulbert, and D. R. Raman, "Fungal production of eicosapentaenoic and arachidonic acids from industrial waste streams and crude soybean oil," Bioresource Technology, vol. 67, no. 2, pp. 101-110, 1999.

[14] X. Song, X. Zhang, C. Kuang, L. Zhu, and N. Guo, “Optimization of fermentation parameters for the biomass and DHA production of Schizochytrium limacinum OUC88 using response surface methodology," Process Biochemistry, vol. 42, no. 10, pp. 1391-1397, 2007.

[15] H. C. Lichstein and M. H. Soule, "Studies of the effect of sodium azide on microbic growth and respiration. II. The action of sodiuim azide on bacterial catalase," Journal of Bacteriology, vol. 47, no. 3, pp. 231-238, 1944.

[16] J. A. Teixeira and M. Mota, "Determination of catalase activity and its inhibition by a simple manometric method," Biochemical Education, vol. 20, no. 3, pp. 174-175, 1992.

[17] T. Nishida, Y. Orikasa, K. Watanabe, and H. Okuyama, "The cell membrane-shielding function of eicosapentaenoic acid for Escherichia coli against exogenously added hydrogen peroxide," FEBS Letters, vol. 580, no. 28-29, pp. 6690-6694, 2006. 
[18] T. Nishida, N. Morita, Y. Yano, Y. Orikasa, and H. Okuyama, "The antioxidative function of eicosapentaenoic acid in a marine bacterium, Shewanella marinintestina IK-1," FEBS Letters, vol. 581, no. 22, pp. 4212-4216, 2007.

[19] S. Bechoua, M. Dubois, Z. Dominguez et al., "Protective effect of docosahexaenoic acid against hydrogen peroxideinduced oxidative stress in human lymphocytes," Biochemical Pharmacology, vol. 57, no. 9, pp. 1021-1030, 1999.

[20] B. Halliwell and J. M. Gutteridge, Free Radicals in Biology and Medicine, Oxford University Press, Oxford, UK, 3rd edition, 1998. 

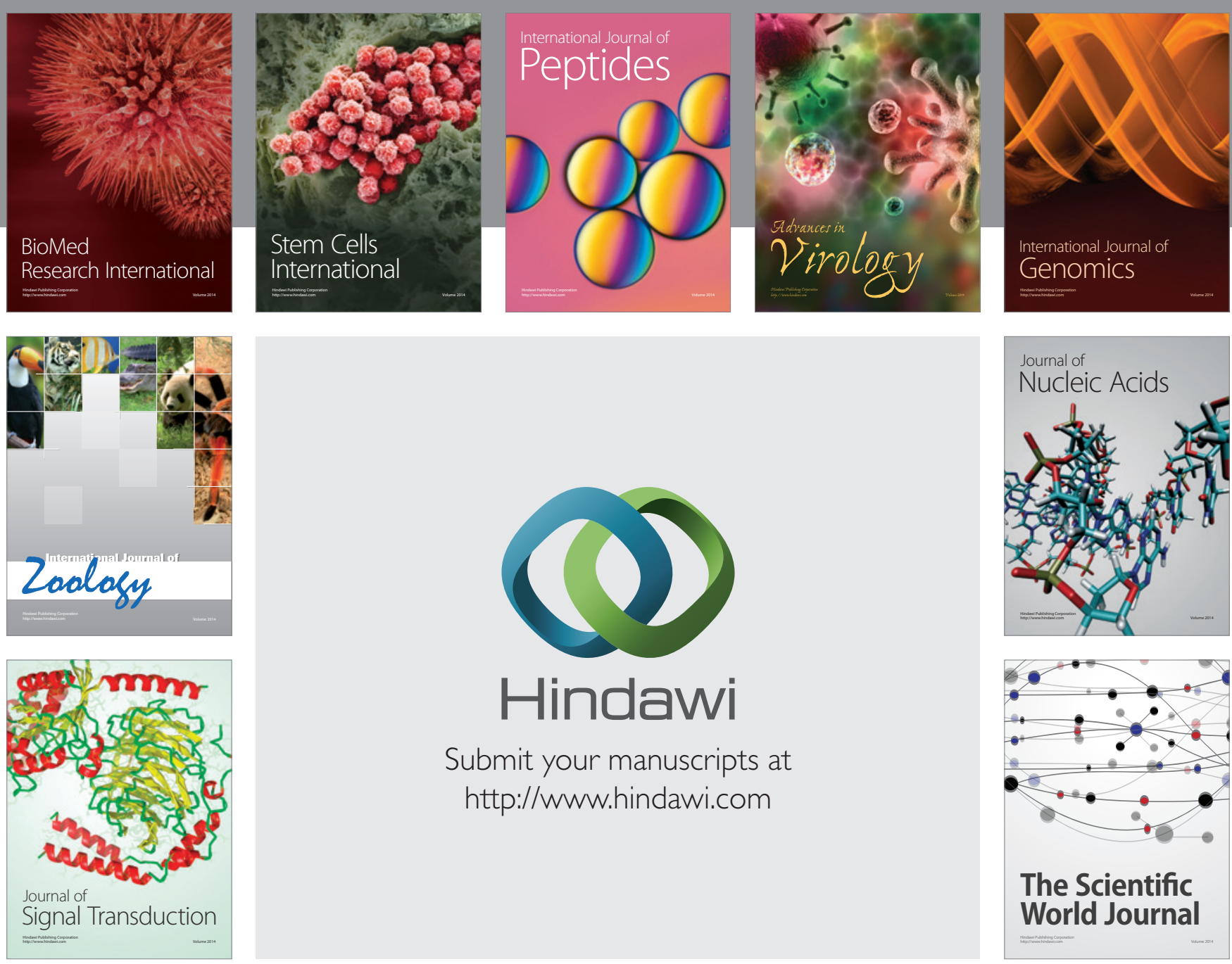

Submit your manuscripts at

http://www.hindawi.com
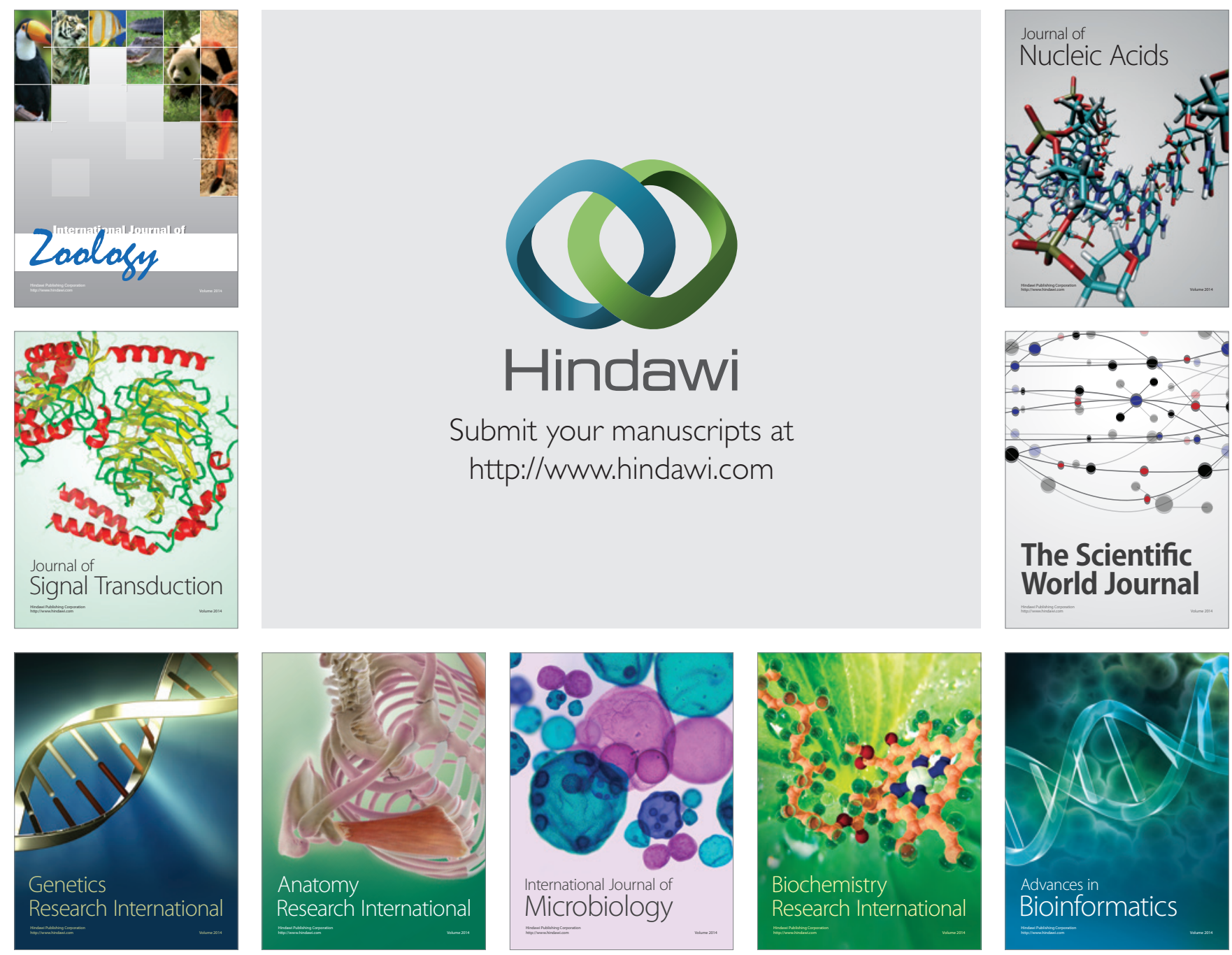

The Scientific World Journal
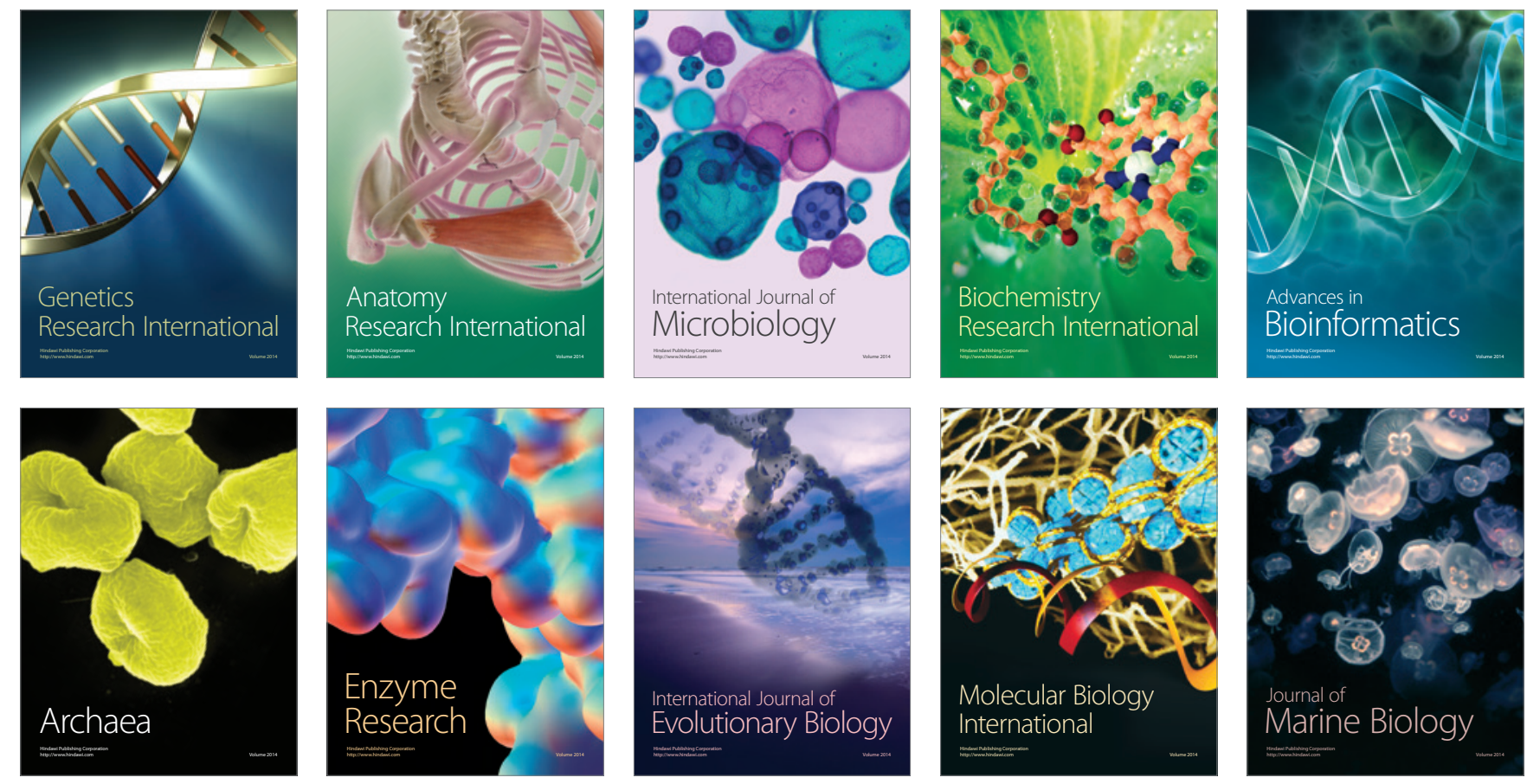